\title{
Asthma and occupation: Diagnosis using serial peak flow measurements
}

\author{
Asma e tRABalho: diagnóstico POR MEdidA SERIADA dO PEAK FLOW
}

Authorship: Brazilian Association of Occupational Medicine (ANAMT)

Participants: José Domingos Neto ${ }^{1}$, Eduardo Myung ${ }^{1}$, Guilherme Murta $^{1}$, Paulo Rogério Lima ${ }^{1}$, Anielle Vieira ${ }^{1}$, Leandro Araújo Lessa ${ }^{1}$, Bruna Rafaela Torres de Carvalho ${ }^{1}$, Renata Buzzini' ${ }^{2}$, Wanderley Marques Bernardo²

Final draft: May 12, 2017

${ }^{1}$ Associação Nacional de Medicina do Trabalho (ANAMT), São Paulo, SP, Brazil

${ }^{2}$ Associação Médica Brasileira (AMB), São Paulo, SP, Brazil

The Guidelines Project, an initiative of the Brazilian Medical Association, aims to combine information from the medical field in order to standardize procedures to assist the reasoning and decision-making of doctors.

The information provided through this project must be assessed and criticized by the physician responsible for the conduct that will be adopted, depending on the conditions and the clinical status of each patient.

\section{EvidenCe COLLeCtion METHOD}

This guideline followed the standard of a systematic review with evidence retrieval based on evidence-based medicine (EBM), so that clinical experience is integrated with the ability to critically analyze and apply scientific information rationally, thus improving the quality of medical care.

We used the structured mode of formulating questions synthesized by the acronym PICO, where P stands for patients with occupational asthma, I for indicator i.e. serial peak flow measurement, and O stands for the outcome of diagnosis.

By raising a relevant question related to the proposed topic, we identified, based on the structured question, the keywords that formed the basis of the search for evidence in the databases: Medline-Pubmed, Lilacs, Labordoc and Cochrane Library. The studies had their abstracts reviewed and after applying the eligibility criteria (inclusion and exclusion), 33 articles were selected in order to answer the clinical doubt (Annex I).

\section{Clinical question}

Is there repercussion on clinical outcomes when applying serial peak flow measurements to diagnose work-related asthma among workers with respiratory symptoms?

\section{Grades OF RECOMMENDATION AND LEVELS OF EVIDENCE}

- A: Experimental or observational studies of higher consistency.

- B: Experimental or observational studies of lower consistency.

- C: Case reports / non-controlled studies.

- D: Opinion without critical evaluation, based on consensus, physiological studies or animal models.

\section{Objective}

This Guideline aims to present and discuss the best scientific evidence currently available regarding the clinical outcomes of work-related asthma diagnosis using a serial peak-flow measure for workers with respiratory symptoms.

\section{INTRODUCTION}

Occupational asthma $(\mathrm{OA})$ is a form of work-related asthma (WRA) characterized by reversible airflow obstruction, bronchial hyperreactivity and airway inflammation, and may be mediated by immunological or non-immunological reactions, resulting from conditions attributable to a certain etiological factor in the work environment. According to population-based studies, $\mathrm{OA}$ is estimated to account for about 10 to 25 percent of adult asthma. ${ }^{1-3}$ 
In this context, $\mathrm{OA}$ is characterized as asthma beginning after exposure to an etiologic factor in the work environment, but there is also another form of WRA that is characterized by pre-existing asthma aggravated or exacerbated as a result of an agent present in the work environment called work aggravated asthma (WAA).

Part of the problem that involves WRA comes from the analysis of observational studies which, in comparing the incidence of this pneumopathy with the records of notifications in several countries, objectively verified its underdiagnosis. ${ }^{4-9}$

Thus, WRA underdiagnosis generates impacts on workers' health, with impairment of quality of life and work capacity, and on economic indicators such as workplace absenteeism and consumption of health resources. ${ }^{10,11}$

In any case, for an adequate diagnosis of WRA, it is essential that the relation between signs and symptoms in an individual with occupational exposure is well established as early as possible. Diagnostic methods for WRA include serial peak flow measurement that is intended to monitor airflow limitation in the presence (period worked) and absence (non-working time) of possible risk factors in the work environment.

In the technical analysis of a diagnostic test, there are some requirements that need to be met for incorporation into medical practice. They include adequate sensitivity (percentage of positive results in a group presenting the disease) and specificity (percentage of negative results in a healthy group). In addition, the diagnostic test should contribute to adequate treatment in order to promote objective modification in the natural history of the disease. ${ }^{12}$

Therefore, given the magnitude, underdiagnosis and impact of WRA in the clinical practice of the occupational physician, this guideline is intended to present and discuss the best available scientific evidence on the effectiveness of WRA diagnosis using serial peak flow measurement for workers with respiratory symptoms.

\section{Data extraction}

Is there repercussion on clinical outcomes when applying serial peak flow measurements to diagnose work-related asthma among workers with respiratory symptoms?

The selected articles were reviewed in order to calculate the sensitivity and specificity for WRA diagnosis. We found a sensitivity of $82 \%$ (95CI 76-90\%) and a specificity of $88 \%(95$ CI $80-95 \%) .{ }^{13-40}(\mathbf{B})$

The gold standard used in the diagnostic test studies was broncoprovocation with specific agents and forced expiratory volume measurement in the first second (FEV1). FEV1 was more sensitive to assess asthma alterations than peak flow; however, respiratory maneuvers for FEV1 were considered less reliable when not personally supervised by a health professional and thus less reproducible in cases of serial measurements at work and outside work. In contrast, serial peak flow measurements were more reliable and more reproducible in the unsupervised diagnostic format. ${ }^{41}(\mathbf{A})$

For adequate assessment, in an individual with suspected WRA, serial peak flow measurements should be indicated at the onset of the pulmonary condition and should monitor airflow limitation during the work period compared to periods away from work. A wide variety of specific protocols have been described for satisfactory measurement, including peak flow measurements at least four times a day over two weeks at the workplace, presumably due to respiratory symptoms, and for two weeks in settings away from the work environment. ${ }^{42}(\mathbf{A})$

The rate of return of serial peak flow measurements was adequate containing $61 \%$ of measures returned for analysis with interpretable and acceptable data for WRA diagnosis. ${ }^{41}(\mathbf{A})$

The rate of return of serial measurements can be improved when the employee receives face-to-face instructions rather than only written instructions. In addition, the result can be further optimized when the employee uses a registration card to point out measurement frequencies and periods. ${ }^{41}(\mathbf{A})$

Data interpretation can be performed with visual analysis of the information by a trained specialist. However, software-based interpretation improves data analysis. ${ }^{41}$ (A) One of the softwares available for analysis of serial peak flow measurements is Oasys.

Limitations of the application of serial peak flow measurements include: the need for worker collaboration to obtain satisfactory records, the presence of functional illiteracy rendering it impossible to record the information, and the non-applicability of the method to severe episodes of asthma while in the work environment. ${ }^{41,43,44}(\mathbf{A})$

However, when these potential sources of error are understood, serial peak flow measurement is a viable, useful and low-cost method for diagnosing WRA, mainly due to adequate specificity, sensitivity, rate of return of the measurements, possibility to analyze other differential diagnoses and possibility of associating labor activity with the presence of respiratory symptoms. ${ }^{45}(\mathbf{A})$

Diagnosis of WRA is largely important for both primary prevention and tertiary prevention in the workplace. Regarding primary prevention, even the diagnostic elucidation of a single case of WRA in a group of workers sharing similar occupational exposures offers the possibility 
of reassessing occupational hazards in the workplace, thereby offering individual and/or collective protective measures to prevent the incidence of new cases. As for tertiary prevention, the diagnostic elucidation of WRA in a specific case subsidizes the occupational physician with technical information to guarantee the control of presumed factors in the work environment that might be generating disease, exacerbation or aggravation and, thus, allow decision-making, in the sense of avoiding the presumed exposure with professional rehabilitation or readaptation of specific cases in a different work location. ${ }^{42}(\mathbf{A})$

\section{ReCOMmendation}

The analysis of the selected articles indicates that there is sufficient scientific evidence to strongly recommend the application of serial peak flow measurements with a moderate impact on the diagnosis of work-related asthma. Serial peak flow measurement should be applied in the presence of suspected work-related asthma, i.e. when there are respiratory symptoms. Thus, our recommendation is to use the method in a diagnostic format, which does not apply to asymptomatic populations in the screening format.

\section{Conflict of InTERest}

No conflict of interest was stated by the participants who developed this guideline.

\section{REFERENCES}

1. Blanc PD, Toren K. How much adult asthma can be attributed to occupational factors? Am J Respir Crit Care Med. 1999; 107(6):580-7.

2. Balmes J, Becklake M, Blanc P, Henneberger P, Kreiss K, Mapp C, et al. ; Environmental and Occupational Health Assembly, American Thoracic Society. American Thoracic Society Statement: Occupational contribution to the burden of airway disease. Am J Respir Crit Care Med. 2003; 167(5):787-97.

3. Torén K, Blanc PD. Asthma caused by occupational exposures is common-a systematic analysis of estimates of the population attributable fraction. BMC Pulm Med. 2009; 9:7.

4. McDonald JC, Chen Y, Zekveld C, Cherry NM. Incidence by occupation and industry of acute work related respiratory diseases in the UK, 1992-2001. Occup Environ Med. 2005; 62(12):836-42.

5. Bakerly ND, Moore VC, Vellore AD, Jaakkola MS, Robertson AS, Burge PS. Fifteen-year trends in occupational asthma: data from the Shield surveillance scheme. Occup Med (Lond). 2008; 58(3):169-74.

6. Orriols R, Costa R, Albanell M, Alberti C, Castejon J, Monso E, et al.; Malaltia Ocupacional Respiratória (MOR) Group. Reported occupational respiratory diseases in Catalonia. Occup Environ Med. 2006; 63(4):255-60.

7. Karjalainen A, Kurppa K, Virtanen S, Keskinen H, Nordman H. Incidence of occupational asthma by occupation and industry in Finland. Am J Ind Med. 2000; 37(5):451-8.

8. Ameille J, Pauli G, Calastreng-Crinquand A, Vervloët D, Iwatsubo Y, Popin E, et al.; Observatoire National des Asthmes Professionnels. Reported incidence of occupational asthma in France, 1996-99: the ONAP programme. Occup Environ Med. 2003; 60(2):136-41.

9. Esterhuizen TM, Hnizdo E, Rees D. Occurrence and causes of occupational asthma in South Africa-results from SORDSA's Occupational Asthma Registry, 1997-1999. S Afr Med J. 2001; 91(6):509-13.
10. Blanc PD, Cisternas M, Smith S, Yelin EH. Asthma, employment status, and disability among adults treated by pulmonary and allergy specialists. Chest 1996; 109(3):688-96.

11. Blanc PD, Trupin L, Eisner M, Earnest G, Katz PP, Israel L, et al. The work impact of asthma and rhinitis: findings from a population-based survey. J Clin Epidemiol 2001; 54(6):610-8.

12. Gordis L. Epidemiology. 5 ed. Philadelphia: Elsevier Saunders; 2014.

13. Moore VC, Jaakkola MS, Burge CB, Pantin CF, Robertson AS, Burge PS. Do long periods off work in peak expiratory flow monitoring improve the sensitivity of occupational asthma diagnosis? Occup Environ Med. 2010; 67(8):562-7.

14. Burge CB, Moore VC, Pantin CF, Robertson AS, Burge PS. Diagnosis of occupational asthma from time point differences in serial PEF measurements. Thorax. 2009; 64(12):1032-6.

15. Moore VC, Jaakkola MS, Burge CBSG, Robertson AS, Pantin CFA, Dev Vellore A, et al. A new diagnostic score for occupational asthma; the area between the curves (ABC score) of PEF on days at and away from work. Chest. 2009; 135(2):307-14.

16. Moore VC, Jaakkola MS, Burge CB, Pantin CF, Robertson AS, Vellore AD, et al. $\mathrm{PEF}$ analysis requiring shorter records for occupational asthma diagnosis. Occup Med (Lond). 2009; 59(6):413-7.

17. Moore VC, Cullinan P, Sadhra S, Burge PS. Peak expiratory flow analysis in workers exposed to detergent enzymes. Occup Med (Lond). 2009; 59(6):418-23.

18. Park D, Moore VC, Burge CB, Jaakkola MS, Robertson AS, Burge PS. Serial PEF measurement is superior to cross-shift change in diagnosing occupational asthma. Eur Respir J. 2009; 34(3):574-8.

19. Sauni R, Kauppi P, Helaskoski E, Virtema P, Verbeek J. Audit of quality of diagnostic procedures for occupational asthma. Occup Med (Lond). 2009; 59(4):230-6.

20. Hayati F, Maghsoodloo S, DeVivo MJ, Thomas RE, Lemiere C. Quality control chart method for analyzing PEF variability in occupational asthma. Am J Ind Med. 2008; 51(3):223-8.

21. Bolen AR, Henneberger PK, Liang X, Sama SR, Preusse PA, Rosiello RA, et al. The validation of work-related self-reported asthma exacerbation. Occup Environ Med. 2007; 64(5):343-8.

22. Chiry S, Cartier A, Malo JL, Tarlo SM, Lemiere C. Comparison of peak expiratory flow variability between workers with work-exacerbated asthma and occupational asthma. Chest. 2007; 132(2):483-8.

23. Hannu T, Piipari R, Tuppurainen M, Nordman H, Tuomi T. Occupational asthma caused by stainless steel welding fumes: a clinical study. Eur Respir J. 2007; 29(1):85-90.

24. Minov J, Karadzinska-Bislimovska J, Vasilevska K, Risteska-Kuc S, Stoleski S. Occupational asthma in subjects occupationally exposed to herbal and fruit tea dust. Arh Hig Rada Toksikol. 2007; 58(2):211-21.

25. Robertson W, Robertson A, Burge C, Moore VC, Jaakkola MS, Dawkins PA, et al. Clinical investigation of an outbreak of alveolitis and asthma in a car engine manufacturing plant. Thorax. 2007; 62:981-90.

26. Hayati F, Maghsoodloo S, DeVivo MJ, Carnahan BJ. Control chart for monitoring occupational asthma. J Safety Res. 2006; 37(1):17-26.

27. Medina-Ramón M, Zock JP, Kogevinas M, Sunyer J, Basagaña X, Schwartz $\mathrm{J}$, et al. Short-term respiratory effects of cleaning exposures in female domestic cleaners. Eur Respir J. 2006; 27(6):1196-203.

28. Eifan AO, Derman O, Kanbur N, Sekerel BE, Kutluk T. Occupational asthma in apprentice adolescent car painters. Pediatr Allergy Immunol. 2005; 16(8):662-8.

29. Huggins V, Anees W, Pantin CFA, Burge PS. Improving the quality of peak flow measurements for the diagnosis of occupational asthma. Occup Med (Lond). 2005; 55(5):385-8.

30. Anees W, Gannon PF, Huggins V, Pantin CFA, Burge PS. Effect of peak expiratory flow data quantity on diagnostic sensitivity and specificity in occupational asthma. Eur Respir J. 2004; 23(5):730-4.

31. Hollander A, Heederik D, Brunekreef B. Work-related changes in peak expiratory flow among laboratory animal workers. Eur Respir J. 1998; 11(4):929-36.

32. Leroyer C, Perfetti L, Trudeau C, L'Archevěque J, Chan Yeung M, Malo JL. Comparison of serial monitoring of peak expiratory flow and FEV1 in the diagnosis of occupational asthma. Am J Respir Crit Care Med. 1998; 158(3):827-32

33. Gannon PFG, Newton DT, Belcher J, Pantin CF, Burge PS. Development of OASYS-2, a system for the analysis of serial measurements of peak expiratory flow in workers with suspected occupational asthma. Thorax. 1996; 51(5):484-9. 
34. Malo J, Trudeau C, Ghezzo H, L'Archevěque J, Cartier A. Do subjects investigated for occupational asthma through serial peak expiratory flow measurements falsify their results? J Allergy Clin Immunol. 1995; 96(5 Pt 1):601-7.

35. Quirce S, Contreras G, Dybuncio A, Chan-Yeung M. Peak expiratory flow monitoring is not a reliable method for establishing the diagnosis of occupational asthma. Am J Respir Crit Care Med. 1995; 152(3):1100-2.

36. Cote J, Kennedy S, Chan-Yeung M. Quantitative versus qualitative analysis of peak expiratory flow in occupational asthma. Thorax. 1993; 48(1):48-51.

37. Malo JL, Côté J, Cartier A, Boulet L, L'Archevěque J, Chan-Yeung M. How many times per day should peak expiratory flow rates be assessed when investigating occupational asthma? Thorax. 1993; 48(12):1211-7.

38. Liss GM, Tarlo SM. Peak expiratory flow rates in possible occupational asthma. Chest. 1991; 100(1):63-9.

39. Côté J, Kennedy SM, Chan-Yeung M. Sensitivity and specificity of PC20 and peak expiratory flow rate in cedar asthma. J Allergy Clin Immunol. 1990; 85(3):592-8.

40. Revsbech P, Anderson G. Diurnal variation in peak expiratory flow rate among grain elevator workers. Br J Ind Med. 1989; 46(8):566-9.

41. Moore VC, Jaakkola MS, Burge PS. A systematic review of serial peak expiratory flow measurements in the diagnosis of occupational asthma. Annals of Respiratory Medicine. 2010; 1:31-44.

42. Tarlo SM, Balmes J, Balkissoon R, Beach J, Beckett W, Bernstein D, et al. Diagnosis and management of work-related asthma: American College of Chest Physicians Consensus Statement. Chest 2008; 134(3 Suppl):1S-41S.

43. Jolly AT, Klees JE, Pacheco KA, Guidotti TL, Kipen HM, Biggs JJ, et al. WorkRelated Asthma. J Occup Environ Med. 2015; 57(10):e121-9.

44. Nicholson PJ, Cullinan P, Taylor AJN, Burge PS, Boyle C. Evidence based guidelines for the prevention, identification, and management of occupational asthma. Occup Environ Med. 2005; 62(5):290-9.

45. Baur X, Sigsgaard T, Aasen TB, Burge PS, Heederik D, Henneberger P, et al.; ERS Task Force on the Management of Work-related Asthma. Guidelines for the management of work-related asthma. Eur Respir J. 2012; 39(3):529-45.

46. Brouwers M, Kho ME, Browman GP, Burgers JS, Cluzeau F, Feder G, et al.; AGREE Next Steps Consortium. AGREE II: Advancing guideline development, reporting and evaluation in health care. CMAJ. 2010; 182(18):E839-42.

47. Scottish Intercollegiate Guidelines Network. SIGN 50 methodology checklist 5: studies of diagnostic accuracy. 2008. Available from: http://www.sign. ac.uk/guidelines/fulltext/50/checklist5.html.

48. Levels of Evidence and Grades of Recommendations - Oxford Centre for Evidence Based Medicine. Available from: http://cebm.jr2.ox.ac.uk/docs/old_levels.htm.

49. Goldet G, Howick J. Understanding GRADE: an introduction. J Evid Based Med. 2013; 6(1):50-4.

\section{AnNex I}

\section{Structured question}

The clinical question was structured based on the PICO components: $\mathrm{P}$ (patient), I (intervention), C (comparison), $\mathrm{O}$ (outcome).

- $\mathbf{P}$ - Occupational asthma

- I - Serial peak flow measurements

- $\mathrm{C}-$

- $\mathbf{O}$ - Diagnosis

\section{Search strategy}

The scientific databases consulted were:

\section{PubMed-Medline}

- (Occupational Asthma) AND (Peak Expiratory Flow OR Peak Flow) AND (Diagnosis)

\section{Cochrane}

- (Occupational Asthma) AND (Peak Expiratory Flow OR Peak Flow) AND (Diagnosis)

Lilacs

- Asma Ocupacional AND Peak Expiratory Flow AND Diagnosis

Labordoc

- (Occupational Asthma) AND (Peak Expiratory Flow) AND Diagnosis

\section{Articles retrieved}

A total of 1,011 articles were retrieved by 3/12/2017 (Table 1); 433 articles were retrieved from Medline; 522 articles were retrieved from Labordoc; 54 articles were retrieved from Cochrane; two articles were retrieved from Lilacs. Seven articles were found in duplicate in the Medline and Labordoc databases.

TABLE 1 Absolute and relative distribution of the search results of references according to database.

\begin{tabular}{lll} 
Database & $\begin{array}{l}\mathbf{N}^{\circ} \text { of studies } \\
\text { retrieved }\end{array}$ & $\begin{array}{l}\mathbf{N}^{\circ} \text { of studies } \\
\text { selected }\end{array}$ \\
\hline PubMed/Medline & 433 & 19 \\
\hline Labordoc & 522 & 16 \\
\hline Cochrane & 54 & 0 \\
\hline Lilacs & 2 & 0 \\
\hline Verification of reference lists & --- & 5 \\
\hline Repeated & --- & 7 \\
\hline Total & 1,011 & 33 \\
\hline
\end{tabular}

After the evidence retrieval process, the results were independently classified by two researchers who decided whether the title and abstract of the study covered the scope proposed for this guideline. The studies that did not reach agreement of both evaluators were read by a third evaluator in order to define for inclusion or exclusion of the study in the review.

After reading the full articles, the studies were selected according to inclusion and exclusion criteria. To complement the search strategy, we analyzed the reference lists of the selected articles and included five more articles. After completing this stage, 33 articles were selected, of which 28 were diagnostic test articles and other five were articles based on the systematic literature review model. 
Inclusion criteria for selected studies

In order to be included in the evidence analysis step, the retrieved studies were required to be in line with the clinical question raised for this study.

\section{Study design}

Narrative reviews, case reports and studies presenting preliminary results only were excluded from selection.

\section{Language}

We included studies available in Portuguese and/or English.

\section{According to publication}

Only full-text studies were considered for critical assessment. There was no time limit for retrieval of articles.

\section{Evidence selected based on critical assessment}

The quality of the scientific evidence was analyzed after applying the inclusion and exclusion criteria. The selected articles were defined as systematic reviews of the literature and diagnostic test studies. All evidence selected under the methodological format of a systematic review of the literature were submitted to an appropriate critical evaluation checklist, allowing the classification of the study according to the AGREE II score (Table 2) ${ }^{46}$ Diagnostic test studies were critically analyzed for quality of evidence based on QUADAS 2 (Table 3). ${ }^{47}$

\section{Exposure of the results}

In order to present the results, we evaluated the selected scientific evidence by specifically considering the nuances of the population, intervention and outcomes, including the presence or absence of benefit and/or harm and the controversies related to the application of that specific intervention.

\section{Exposure of the recommendations}

In order to present the recommendations, we adopted the suggested clinical conduct of the authors of the technical guideline, considering the characteristics of the synthesis of the evidence, later submitted to validation by all the authors participating in the Working Group.

The grade of recommendation stems directly from the available strength of included studies, according to the Oxford scale ${ }^{48}$ and the GRADE system. ${ }^{49}$

TABLE 2 Articles that were selected under the systematic
review format and included critical analysis based on AGREE II.
\begin{tabular}{llll} 
Author & Year & Type of study & Quality \\
\hline Jolly et al. ${ }^{43}$ & 2015 & Systematic review & 6 \\
\hline Baur et al. ${ }^{45}$ & 2012 & Systematic review & 6 \\
\hline Moore et al. ${ }^{41}$ & 2009 & Systematic review & 6 \\
\hline Tarlo et al. ${ }^{42}$ & 2008 & Systematic review & 6 \\
\hline Nicholson et al. ${ }^{44}$ & 2005 & Systematic review & 5
\end{tabular}

Remark 1: AGREE II is a quality analysis method that classifies studies from 1 to 7 based on 23 items for evaluation.

Remark 2: the five studies analyzed were included in the critical analysis.

TABLE 3 Articles that were selected under the diagnostic

test format and included critical analysis based on QUADAS 2.

Author

Year Type of study

Quality

\begin{tabular}{llll}
\hline Moore et al. & 13 & 2010 & Diagnostic test \\
\hline
\end{tabular}

Burger et al. ${ }^{14} \quad 2009 \quad$ Diagnostic test $1+$

Moore et al. I $^{15} \quad 2009 \quad$ Diagnostic test 2+

Moore et al. II $2009 \quad$ Diagnostic test $1+$

Moore et al. III $^{17} \quad 2009 \quad$ Diagnostic test 1 -

Park et al. ${ }^{18} \quad 2009 \quad$ Diagnostic test $2+$

Sauni et al. ${ }^{19} \quad 2009 \quad$ Diagnostic test $1+$

Hayati et al. ${ }^{20} \quad 2008 \quad$ Diagnostic test $1+$

Bolen et al. ${ }^{21} \quad 2007 \quad$ Diagnostic test $1+$

Chiry et al. $^{22} \quad 2007$ Diagnostic test $2+$

Hannu et al. ${ }^{23} \quad 2007 \quad$ Diagnostic test $1+$

\begin{tabular}{llll}
\hline Minov et al. ${ }^{24}$ & 2007 & Diagnostic test & $1+$ \\
\hline
\end{tabular}

Robertson et al. ${ }^{25} \quad 2007 \quad$ Diagnostic test $1+$

Hayati et al. ${ }^{26} \quad 2006 \quad$ Diagnostic test $1+$

Medina-Ramón et al. ${ }^{27} 2006 \quad$ Diagnostic test $1+$

Eifan et al. ${ }^{28} \quad 2005 \quad$ Diagnostic test $1+$

Huggins et al. ${ }^{29} \quad 2005 \quad$ Diagnostic test $1+$

Anees et al. ${ }^{30} \quad 2004 \quad$ Diagnostic test $2+$

Hollander et al. ${ }^{31} \quad 1998$ Diagnostic test $1+$

Leroyer et al. ${ }^{32} \quad 1998 \quad$ Diagnostic test $2+$

Gannon et al. ${ }^{33} \quad 1996 \quad$ Diagnostic test 2+

Malo et al. ${ }^{34} \quad 1995 \quad$ Diagnostic test $1+$

Quirce et al. ${ }^{35} \quad 1995 \quad$ Diagnostic test $1+$

Cote et al. ${ }^{36} \quad 1993 \quad$ Diagnostic test 2+

\begin{tabular}{llll}
\hline Malo et al. ${ }^{37}$ & 1993 & Diagnostic test & $2+$ \\
\hline Liss et al. $^{38}$ & 1991 & Diagnostic test & $2+$ \\
\hline Cote et al. ${ }^{39}$ & 1990 & Diagnostic test & $2+$ \\
\hline Revsbech et al. ${ }^{40}$ & 1989 & Diagnostic test & $1+$ \\
\hline
\end{tabular}

Remark 1: QUADAS 2 is a quality analysis method that classifies diagnostic test studies. The general methodological evaluation of the studies uses the following quality criteria: high $(2+)$ (most of the criteria met), acceptable (1+) (most of the criteria were met), low (1-), and unacceptable (most of the unmet criteria).

Remark 2: the 28 studies analyzed were included in the critical analysis. 